\title{
Effective isopropanol-butanol (IB) fermentation with high butanol content using a newly isolated Clostridium sp. A1424
}

Sung Hun Youn ${ }^{1}$, Kyung Min Lee ${ }^{1}$, Ki-Yeon Kim', Sun-Mi Lee ${ }^{1,2}$, Han Min Woo ${ }^{3}$ and Youngsoon Um $m^{1,2^{*}}$

\begin{abstract}
Background: Acetone-butanol-ethanol fermentation has been studied for butanol production. Alternatively, to achieve acetone-free butanol production, use of clostridium strains producing butanol and 1,3-propanediol (1,3-PDO) from glycerol, natural and engineered isopropanol-butanol-ethanol (IBE) producers has been attempted; however, residual 1,3-PDO and acetone, Iow IBE production by natural IBE producers, and complicated gene modification are limitations.
\end{abstract}

Results: Here, we report an effective isopropanol and butanol (IB) fermentation using a newly isolated Clostridium sp. A1424 capable of producing IB from various substrates with a small residual acetone. Notably, this strain also utilized glycerol and produced butanol and 1,3-PDO. After $46.35 \mathrm{~g} / \mathrm{L}$ of glucose consumption at pH 5.5-controlled batch fermentation, Clostridium sp. A1424 produced $9.43 \mathrm{~g} / \mathrm{L}$ of butanol and $13.92 \mathrm{~g} / \mathrm{L}$ of IB at the productivity of 0.29 and $0.44 \mathrm{~g} / \mathrm{L} / \mathrm{h}$, respectively, which are the highest values in glucose-based batch fermentations using natural IB producers. More interestingly, using glucose-glycerol mixtures at ratios ranging from 20:2 to 14:8 led to not only acetonefree and 1,3-PDO-free IB fermentation but also enhanced IB production along with a much higher butanol content (butanol/isopropanol ratio of 1.81 with glucose vs. 2.07-6.14 with glucose-glycerol mixture). Furthermore, when the mixture of glucose and crude glycerol at the ratio of 14:8 (total concentration of $35.68 \mathrm{~g} / \mathrm{L}$ ) was used, high butanol/ isopropanol ratio (3.44) and butanol titer ( $9.86 \mathrm{~g} / \mathrm{L})$ were achieved with 1.4 -fold enhanced butanol yield $(0.28 \mathrm{~g} / \mathrm{g})$ and productivity $(0.41 \mathrm{~g} / \mathrm{L} / \mathrm{h})$ compared to those with glucose only at $\mathrm{pH} 5.5$.

Conclusions: A newly isolated Clostridium sp. A1424 was able to produce butanol and isopropanol from various carbon sources. The productivity and titer of butanol and total alcohol obtained in this study were higher than the previously reported results obtained using other natural IB producers. Use of the mixture of glucose and glycerol was successful to achieve acetone-free, 1,3-PDO-free, and enhanced IB production with higher yield, productivity, and selectivity of butanol compared to those with glucose only, providing great advantages from the perspective of carbon recovery to alcohols. This notable result could be accomplished by isolating an effective IB producer Clostridium sp. A1424 as well as by utilizing glucose-glycerol mixtures.

Keywords: Clostridium sp. A1424, Butanol, Isopropanol, Mixture of glucose and glycerol, Crude glycerol

\section{Background}

The $\mathrm{C}_{4}$ alcohol $n$-butanol is broadly used as an intermediate of pharmaceuticals and polymers; an extractant

\footnotetext{
${ }^{*}$ Correspondence: yum@kist.re.kr

${ }^{1}$ Clean Energy Research Center, Korea Institute of Science

and Technology (KIST), Hwarangno 14-gil 5, Seongbuk-gu, Seoul 02792,

South Korea

Full list of author information is available at the end of the article
}

of antibiotics, hormones, and vitamins; and a swelling agent in textiles $[1,2]$. Until now, it has been industrially produced through petrochemical processes [3]. Bio-butanol production was started in the 1900s via acetone-butanol-ethanol (ABE) fermentation using clostridia. The main aim of this process, particularly during the periods of the first and second world wars, was the production of acetone for manufacturing cordite [4]. 
As bio-butanol has received great attention because of its suitable properties as an alternative and renewable fuel [3], the efficient production of bio-butanol has been widely studied through the bioprocess engineering and the strain development $[2,5,6]$. Acetone accounting for $20-30 \%$ of $A B E$ production is considered as an undesirable product because of its corrosiveness and poor fuel properties [1]. For this reason, there has been much effort to reduce or eliminate the production of acetone by interrupting the acetone pathway using genetic manipulation. However, disruption of the genes responsible for acetone formation led not only to less acetone production but also decreased butanol production with the accumulation of acetic acid, butyric acid, or ethanol [7-9].

Alternatively, butanol production has been investigated with non-acetone producing Clostridium pasteurianum, which is capable of producing butanol and 1,3-propanediol (1,3-PDO) from glycerol [10-14]. Crude glycerol generated from biodiesel manufacture has emerged as a low cost substrate generating a high level of the reducing equivalents required for the production of reduced metabolites such as butanol [2]. Although $C$. pasteurianum is different from other butanol-producing clostridia in terms of utilizing glycerol as a sole carbon source for butanol production, it also produces 1,3-PDO as a major byproduct, instead of acetone. Attempts have been made to decrease the production of 1,3-PDO using a chemically mutated strain [15] and using a mixture of glucose and glycerol as substrates [16, 17]; but a certain amount of 1,3-propanediol was still produced.

Butanol can also be produced through isopropanolbutanol-ethanol (IBE) fermentation with a small residual amount of acetone by wild-type strains [18-20] and engineered strains $[1,21,22]$. Isopropanol in the mixed alcohols can be utilized as a fuel additive [20]. However, there are only a few natural IBE producers reported to date, including Clostridium beijerinckii NRRL B-593 $[19,20]$ and Clostridium beijerinckii optinoii [18], and they show low production of butanol and alcohols even after process optimization [18, 20, 23]. Another approach is to genetically engineer $\mathrm{ABE}$ strains by expressing the isopropanol dehydrogenase from C. beijerinckii NRRL B-593 [1, 21, 22]. However, overexpression of isopropanol dehydrogenase alone caused an incomplete conversion of acetone to isopropanol and decrease of butanol production [1, 21, 22, 24]. Multiple genes had to be modified to restore butanol production [1,24, 25]. Because genetic modification of solventogenic clostridia is far more challenging than for other better known microorganisms, isolating superior new natural IBE producers would widen the feasibility of efficient IBE fermentation.

Here, we report a newly isolated Clostridium sp. A1424 which is able to perform isopropanol-butanol
(IB) fermentation along with a small amount of acetone using glucose. Unlike other solventogenic clostridia, this strain utilizes glycerol as the sole carbon source and produces butanol and 1,3-PDO as a byproduct. The effects of carbon source, glucose concentration, and $\mathrm{pH}$ on $\mathrm{IB}$ production of Clostridium sp. A1424 were evaluated. Notably, using a mixture of glucose and glycerol resulted in (i) enhanced IB production, (ii) much higher butanol contents, (iii) no residual acetone, and (iv) no 1,3-PDO production even in the presence of glycerol. This is the first report of success in increasing butanol content and decreasing isopropanol production simultaneously in IB fermentation. The results presented here suggest that the use of the high IB producing strain Clostridium sp. A1424 and process optimization would be a good strategy for industrial application of IB fermentation towards higher butanol content.

\section{Results and discussion}

\section{Identification of Clostridium sp. A1424}

A total of six colonies producing butanol were obtained from the soil samples. Among them, a bacterium producing butanol and isopropanol from glucose was isolated. Based on its $16 \mathrm{~S}$ rRNA sequence and phylogenetic analysis, the isolate was found to belong to the genus Clostridium and to be very closely related to C. beijerinckii NCIMB $8052^{\mathrm{T}}$ and Clostridium diolis DSM $5431^{\mathrm{T}}$ (Fig. 1), with almost identical 16S rRNA sequence similarity $(99.92 \%)$ to both strains (Table 1 ), and was designated Clostridium sp. A1424. However, this strain was distinguished from C. beijerinckii NCIMB $8052^{\mathrm{T}}$ and C. diolis DSM $5431^{\mathrm{T}}$ by its physiological differences in metabolite production from glucose and glycerol (Table 1). Clostridium beijerinckii NCIMB $8052^{\mathrm{T}}$ produces butanol and acetone as the main products using glucose, but it cannot utilize glycerol as a sole carbon source $[26,27]$. Clostridium diolis DSM $5431^{\mathrm{T}}$ mainly produces butyric acid and acetic acid from glucose and it can utilize glycerol, yielding 1,3-PDO [28, 29]. On the other hand, Clostridium sp. A1424 showed significantly different features: it mainly produced butanol and isopropanol from glucose and butanol and 1,3-PDO from glycerol. The fermentation products of non-type strains of solventogenic clostridia including natural IB producers were also compared with those of Clostridium sp. A1424 in Table 1. When glycerol is supplied as a sole carbon source, C. beijerinckii NRRL B-593 mainly produces 1,3PDO and a small amount of ethanol and 2,3-butanediol [30]. Study on the glycerol utilization of C. beijerinckii optinoii has not yet been reported and C. pasteurianum DSM 525 produces acids as the main products from glucose [12]. Because Clostridium sp. A1424 was able to produce butanol as the main product from both glucose 


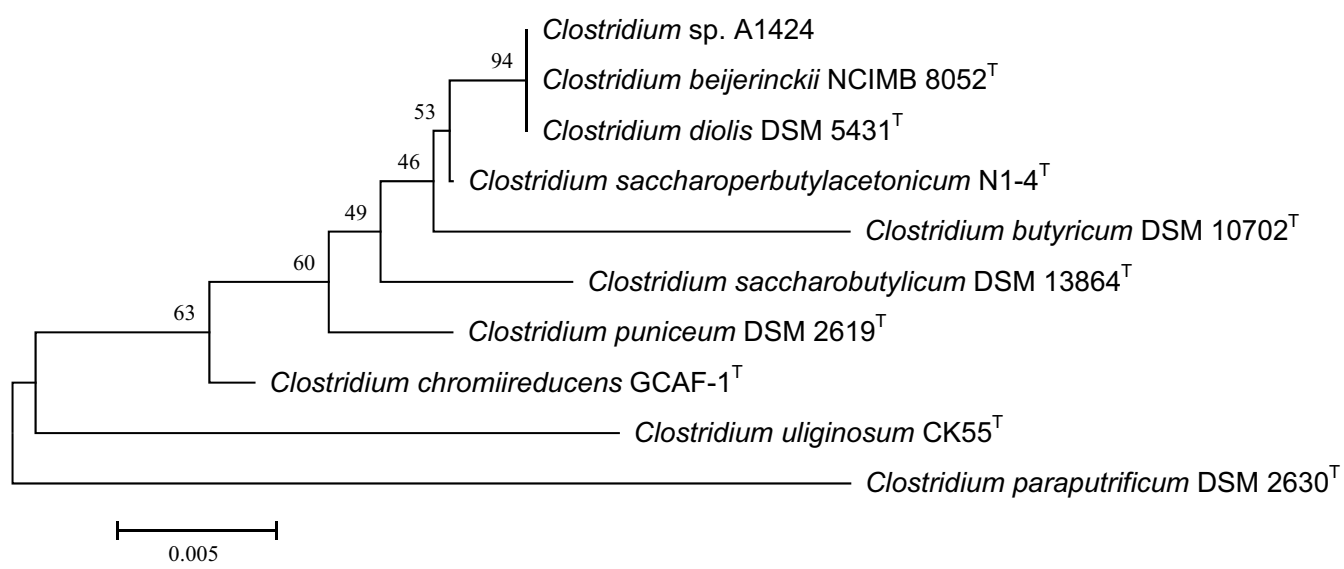

Fig. 1 Phylogenetic tree with Clostridium sp. A1424 and its closely related type strains based on 16S rRNA gene sequences

Table 1 Comparison of fermentation products from glucose and glycerol between Clostridium sp. A1424 and other related clostridia

\begin{tabular}{|c|c|c|c|c|c|}
\hline Strains & $\begin{array}{l}\text { GenBank } \\
\text { accession no. }\end{array}$ & $\begin{array}{l}\text { 16s rRNA } \\
\text { similarity (\%) }\end{array}$ & Substrate & Main products & References \\
\hline \multirow[t]{2}{*}{ Clostridium sp. A1424 } & KT314078 & 100 & Glucose & Butanol, isopropanol & This study \\
\hline & & & Glycerol & Butanol, 1,3-propanediol & \\
\hline \multirow[t]{2}{*}{ C. beijerinckii NCIMB $8052^{\top}$} & СР000721 & 99.92 & Glucose & Butanol, acetone & {$[26,27]$} \\
\hline & & & Glycerol & - & \\
\hline \multirow[t]{2}{*}{ C. diolis DSM $5431^{\top}$} & AJ458418 & 99.92 & Glucose & Butyric acid, acetic acid & {$[28,29]$} \\
\hline & & & Glycerol & 1,3-Propanediol & \\
\hline \multirow[t]{2}{*}{ C. beijerinckii NRRL B-593 } & U16168.1 & $99.82^{\mathrm{a}}$ & Glucose & Butanol, isopropanol & {$[20,30]$} \\
\hline & & & Glycerol & 1,3-Propanediol, ethanol & \\
\hline \multirow[t]{2}{*}{ C. beijerinckii optinoii } & N/A & N/A & Glucose & Butanol, isopropanol & [18] \\
\hline & & & Glycerol & N/A & \\
\hline \multirow[t]{2}{*}{ C. pasteurianum DSM $525^{\top}$} & NR_104822.1 & 92.41 & Glucose & Butyric acid, acetic acid & {$[12,14,17]$} \\
\hline & & & Glycerol & Butanol, 1,3-propanediol & \\
\hline
\end{tabular}

N/A not available

a $16 \mathrm{~S}$ rRNA sequence of C. beijerinckii NRRL B-593 consisting of 550 bp (NCBI Genbank: U16168.1) was used. Other sequences were about 1330 bp

and glycerol and to produce isopropanol from glucose, we further investigated Clostridium sp. A1424 as a potential butanol and isopropanol producer.

\section{Characterization of Clostridium sp. A1424: substrate utilization and metabolite production}

For evaluating carbon source utilization and metabolite production of Clostridium sp. A1424, various carbon sources including hexose (glucose, mannose, fructose, and galactose), pentose (xylose and arabinose), disaccharides (cellobiose and sucrose), and glycerol were tested.

Clostridium sp. A1424 utilized all the tested substrates with varying extent of consumption. Interestingly, Clostridium sp. A1424 exhibited distinct metabolite production patterns depending on carbon sources (Table 2).
Glucose, mannose, fructose, and disaccharides (18$22 \mathrm{~g} / \mathrm{L}$ ) were completely consumed and the main products were butanol and isopropanol, with butanol yields $\left(Y_{\mathrm{B}}\right)$ of $0.21-0.28 \mathrm{~g} / \mathrm{g}$ substrate. The sum of butanol and isopropanol yield $\left(Y_{\mathrm{IB}}\right)$ was $0.31-0.37 \mathrm{~g} / \mathrm{g}$ substrate. The yields are comparable with those of other natural IBE producers $[18,20]$. Fermentation with sucrose showed the highest concentration and yield of butanol among the tested substrates. The fermentation profiles of Clostridium sp. A1424 with those substrates were typical of normal solventogenic fermentation (see Fig. 2a for glucose cultures as a representative example). Butyric acid and acetic acid were produced with $\mathrm{pH}$ drop (i.e., acidogenic phase), and then butanol, isopropanol, and acetone concentration increased by consuming organic acids with $\mathrm{pH}$ 
Table 2 Fermentation products of Clostridium sp. A1424 using various substrates

\begin{tabular}{|c|c|c|c|c|c|c|c|c|c|}
\hline \multirow[t]{2}{*}{ Substrate } & \multirow{2}{*}{$\begin{array}{l}\text { Substrate } \\
\text { consumed (g/L) }\end{array}$} & \multicolumn{6}{|c|}{ Products (g/L) } & \multicolumn{2}{|c|}{ Yield $(g / g)$} \\
\hline & & Butanol & Isopropanol & Acetone & Acetic acid & Butyric acid & 1,3-propanediol & $Y_{\mathrm{B}}^{\mathrm{a}}$ & $Y_{\mathrm{IB}}^{\mathrm{a}}$ \\
\hline Glucose & $21.62_{ \pm 0.06}$ & $4.49_{ \pm 0.04}$ & $2.48_{ \pm 0.06}$ & $0.33_{ \pm 0.03}$ & $0.43_{ \pm 0.06}$ & $0.72_{ \pm 0.02}$ & 0 & 0.21 & 0.32 \\
\hline Mannose & $19.92_{ \pm 0.04}$ & $4.40_{ \pm 0.13}$ & $1.88_{ \pm 0.01}$ & $0.33_{ \pm 0.04}$ & $0.66_{ \pm 0.02}$ & $0.93_{ \pm 0.05}$ & 0 & 0.24 & 0.34 \\
\hline Fructose & $21.63_{ \pm 0.05}$ & $4.38_{ \pm 0.02}$ & $1.63_{ \pm 0.06}$ & $0.19_{ \pm 0.01}$ & $0.85_{ \pm 0.01}$ & $1.49_{ \pm 0.03}$ & 0 & 0.23 & 0.31 \\
\hline Galactose & $5.96_{ \pm 0.14}$ & $0.59_{ \pm 0.01}$ & 0 & 0 & $0.44_{ \pm 0.02}$ & $1.90_{ \pm 0.02}$ & 0 & 0.11 & 0.11 \\
\hline Xylose & $12.81_{ \pm 0.09}$ & $0.87_{ \pm 0.03}$ & 0 & 0 & $0.68_{ \pm 0.02}$ & $4.71_{ \pm 0.00}$ & 0 & 0.08 & 0.08 \\
\hline Arabinose & $8.24_{ \pm 0.04}$ & 0 & 0 & 0 & $0.15_{ \pm 0.01}$ & $4.20_{ \pm 0.05}$ & 0 & 0 & 0 \\
\hline Cellobiose & $20.02_{ \pm 0.04}$ & $4.50_{ \pm 0.02}$ & $2.65_{ \pm 0.00}$ & $0.45_{ \pm 0.01}$ & $0.43_{ \pm 0.01}$ & $0.24_{ \pm 0.01}$ & 0 & 0.23 & 0.37 \\
\hline Sucrose & $18.20_{ \pm 1.13}$ & $5.01_{ \pm 0.04}$ & $1.71_{ \pm 0.02}$ & $0.34_{ \pm 0.02}$ & $0.97_{ \pm 0.00}$ & $0.87_{ \pm 0.07}$ & 0 & 0.28 & 0.37 \\
\hline Glycerol & $18.13_{ \pm 1.10}$ & $3.91_{ \pm 0.19}$ & 0 & 0 & $0.27_{ \pm 0.02}$ & $2.20_{ \pm 0.07}$ & $3.40_{ \pm 0.25}$ & 0.23 & 0.23 \\
\hline
\end{tabular}

The initial substrate concentration was $18-22 \mathrm{~g} / \mathrm{L}$ for each substrate

The fermentation was performed on serum bottle without $\mathrm{pH}$ control

The data were obtained at $28 \mathrm{~h}$ of fermentation except sucrose cultures ( $36 \mathrm{~h}$ )

The values are average and one standard deviation of triplicate experiments

a $Y_{\mathrm{B}}$, butanol yield ( $\mathrm{g}$ butanol/g substrate); $Y_{\mathrm{IB}}$, the sum of butanol and isopropanol yield ( $\mathrm{g}$ [butanol + isopropanol]/g substrate)

rise (i.e., solventogenic phase). The acetone concentration decreased later with time as acetone was likely further converted to isopropanol by isopropanol dehydrogenase with NADPH as a co-factor [1]. On the other hand, in the case of galactose, xylose, and arabinose, Clostridium sp. A1424 mainly produced butyric acid with relatively low substrate consumption and acidogenic $\mathrm{pH}$ profiles (see Additional file 1: Figure S1 for xylose cultures as a representative example). Considering that acetone and isopropanol were not detected in the galactose, xylose, and arabinose cultures, it appeared that acid re-assimilation by CoA transferase [1] might not be triggered. Interestingly, when exogenous acetone was initially added to xylose cultures, acetone was readily converted to isopropanol from the beginning of fermentation (Additional file 2: Figure S2). This result indicates that the co-factor for isopropanol dehydrogenase (e.g., NADPH) was not limiting in these conditions and that isopropanol dehydrogenase was expressed independently to $\mathrm{ABE}$ production-related enzymes that are known such as CoA transferase, alcohol/aldehyde dehydrogenase, and acetoacetate decarboxylase. These are known to be induced together during the solventogenic phase [1].

When glycerol was used as a substrate, the main products were butanol and 1,3-PDO, with butanol yield of $0.23 \mathrm{~g} / \mathrm{g}\left(Y_{\mathrm{B}}\right)$. To date, C. pasteurianum is the only natural butanol producer from glycerol as sole carbon source known [2] with a yield $\left(Y_{\mathrm{B}}\right)$ of $0.25-0.30 \mathrm{~g} / \mathrm{g}[11,12,14$, 17].

To date, two wild-type clostridia strains, C. beijerinckii NRRL B-593 [20] and C. beijerinckii optinoii [18], have already been studied for butanol and isopropanol production; however, there is limited information on the carbon utilization ability and metabolite production patterns of those strains. In this study, Clostridium sp. A1424 was shown to consume various carbon sources. Of interest was that Clostridium sp. A1424 performed IB fermentation or butyric acid-producing fermentation depending on carbon source (Table 2). However, according to preliminary experiments in our lab, supplying varied ratios of mixed sugars with glucose (yielding IB production) and xylose (yielding butyric acid production) to Clostridium sp. A1424 also led to efficient production of butanol and isopropanol $\left(Y_{\mathrm{IB}}=0.30-0.34 \mathrm{~g} / \mathrm{g}\right.$ of total sugar, data not shown). Further study on IB production with mixed sugars derived from lignocellulosic biomass will be conducted to elucidate metabolic regulation in Clostridium sp. A1424.

\section{Effect of glucose concentration on the production of butanol and isopropanol}

Further fermentation studies using serum bottles were performed with $20-60 \mathrm{~g} / \mathrm{L}$ of initial glucose as sole carbon source to investigate the extent of glucose utilization and solvent production.

As shown in Fig. 2a, b, $4.41 \mathrm{~g} / \mathrm{L}$ of butanol and $2.35 \mathrm{~g} / \mathrm{L}$ of isopropanol were the main products after consumption of $21.62 \mathrm{~g} / \mathrm{L}$ glucose after $16 \mathrm{~h}$ with butanol yield $\left(Y_{\mathrm{B}}\right)$ of $0.20 \mathrm{~g} / \mathrm{g}$ and overall butanol productivity of $0.28 \mathrm{~g} / \mathrm{L} / \mathrm{h}$. When the initial glucose concentration was increased to $41.02 \mathrm{~g} / \mathrm{L}$, butanol and isopropanol concentrations were also increased to 8.60 and $3.68 \mathrm{~g} / \mathrm{L}$, respectively, with butanol yield of $0.21 \mathrm{~g} / \mathrm{g}$ and butanol productivity of $0.31 \mathrm{~g} / \mathrm{L} / \mathrm{h}$ at $28 \mathrm{~h}$ (Fig. 2c, d). With the initial glucose concentration of $58.90 \mathrm{~g} / \mathrm{L}$, the production of total alcohol showed no further increase (butanol, $7.47 \mathrm{~g} / \mathrm{L}$; 

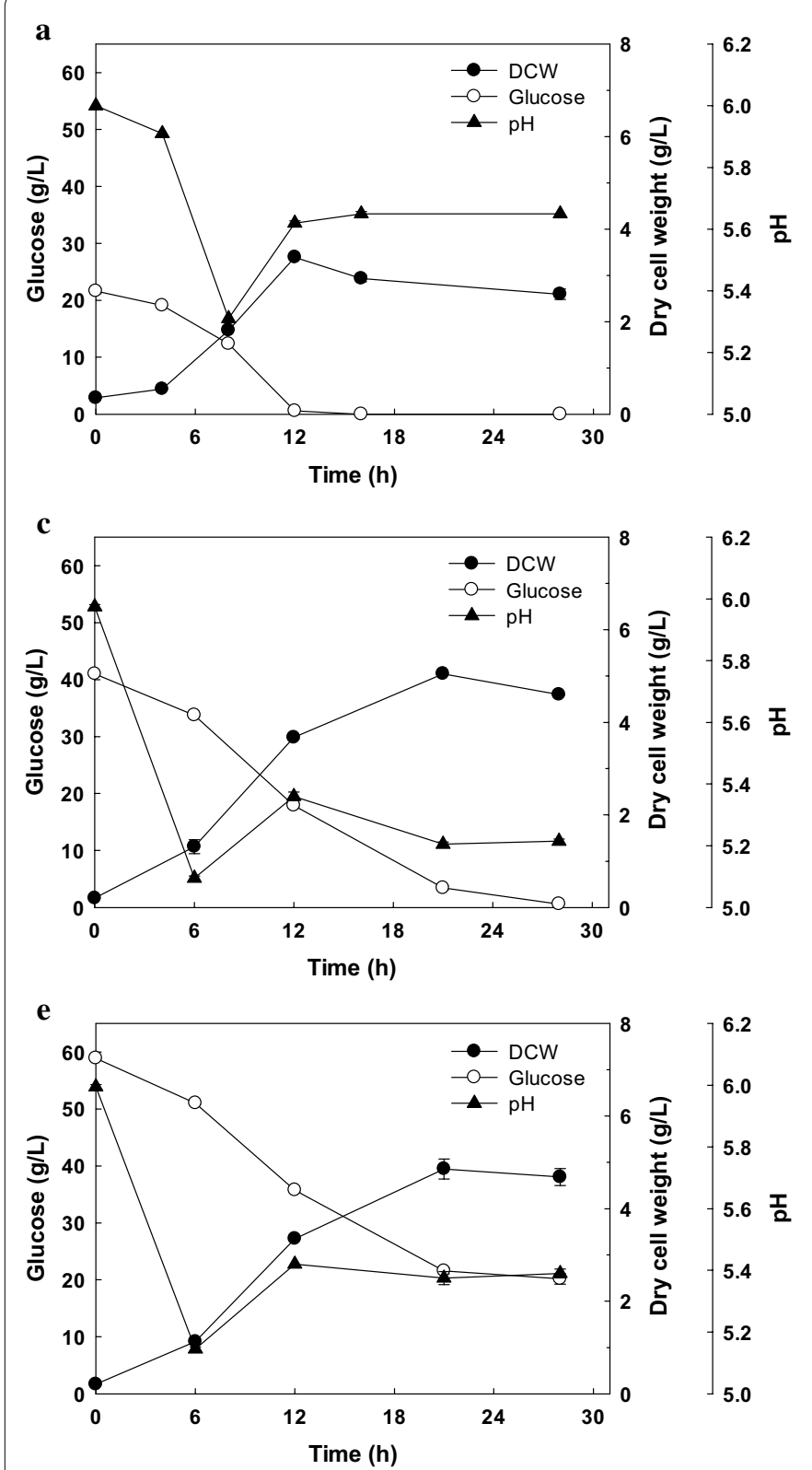
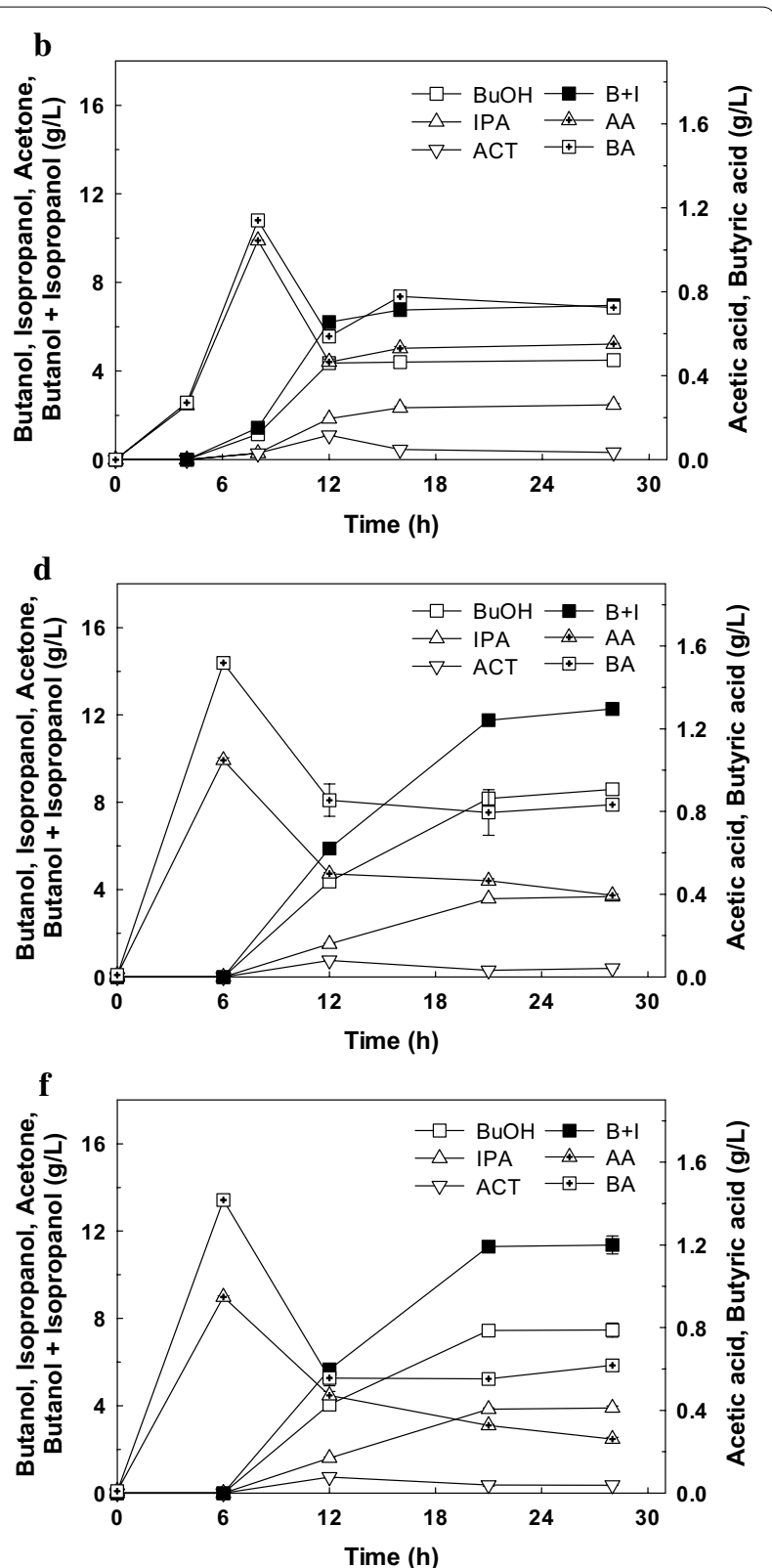

Fig. 2 Isopropanol-butanol fermentation with $21.6 \mathrm{~g} / \mathrm{L}$ initial glucose concentration (a, b), $41.0 \mathrm{~g} / \mathrm{L}$ initial glucose concentration (c, d), and $58.9 \mathrm{~g} / \mathrm{L}$ initial glucose concentration (e, f). DCW dry cell weight, BuOH butanol, IPA isopropanol, $A C T$ acetone, $B+$ / butanol + isopropanol, $A A$ acetic acid, $B A$ butyric acid. The fermentation was performed on serum bottles without $\mathrm{pH}$ control. Error bars represent one standard deviation of triplicate experiments

isopropanol, $3.90 \mathrm{~g} / \mathrm{L}$ ) with incomplete glucose consumption (38.73 g/L) (Fig. 2e, f).

Overall, the butanol yield $\left(Y_{\mathrm{B}}\right)$ and the butanol productivity $\left(P_{\mathrm{B}}\right)$ were $0.19-0.21 \mathrm{~g} / \mathrm{g}$ and $0.27-$ $0.31 \mathrm{~g} / \mathrm{L} / \mathrm{h}$, respectively. In the case of total alcohol (i.e., butanol + isopropanol), the yield $\left(Y_{\mathrm{IB}}\right)$ and the productivity $\left(P_{\mathrm{IB}}\right)$ were $0.29-0.31 \mathrm{~g} / \mathrm{g}$ and $0.41-0.44 \mathrm{~g} / \mathrm{L} / \mathrm{h}$, respectively. Although these results could not be directly compared with other reports employing different cultivation conditions, the concentration and productivity of alcohols by Clostridium sp. A1424 are higher than those of other natural IBE producers in batch fermentation; $C$. beijerinckii NRRL B-593 produced 3.71 and $2.16 \mathrm{~g} / \mathrm{L}$ of butanol and isopropanol, respectively, after $48 \mathrm{~h}$ with low productivity $\left(P_{\mathrm{B}}, 0.08 \mathrm{~g} / \mathrm{L} / \mathrm{h} ; P_{\mathrm{IB}}, 0.12 \mathrm{~g} / \mathrm{L} / \mathrm{h}\right)$ [20], while C. beijerinckii optinoii was shown to produce 6.24 and 
$3.21 \mathrm{~g} / \mathrm{L}$ of butanol and isopropanol, respectively, after $48 \mathrm{~h}\left(P_{\mathrm{B}}, 0.13 \mathrm{~g} / \mathrm{L} / \mathrm{h} ; P_{\mathrm{IB}}, 0.20 \mathrm{~g} / \mathrm{L} / \mathrm{h}\right)[18]$.

Clostridium sp. A1424 appears to produce less butanol than well-known natural ABE producing clostridia such as Clostridium acetobutylicum and C. beijerinckii producing over $10 \mathrm{~g} / \mathrm{L}$ of butanol [26, 31]. However, the butanol productivity obtained with Clostridium sp. A1424 is higher than that with ABE producing clostridia $(0.17-0.23 \mathrm{~g} / \mathrm{L} / \mathrm{h})[26,31]$. Even compared with the results for clostridia mutated and genetically modified to enhance butanol production in ABE fermentation (0.23$0.38 \mathrm{~g} / \mathrm{L} / \mathrm{h}$ ) [5, 6, 32-34], Clostridium sp. A1424 shows comparable butanol productivity $\left(P_{\mathrm{B}}\right)$. Considering that high butanol productivity likely enhances the butanol recovery rate for in situ butanol removal processes (e.g., gas stripping, adsorption) incorporated to reduce butanol inhibition [35], Clostridium sp. A1424 appears a good candidate for butanol production, and an even better one for concomitantly producing isopropanol instead of acetone.

\section{Effect of $\mathrm{pH}$ on butanol and isopropanol production}

As $\mathrm{pH}$ is known to be one of the key factors influencing $\mathrm{ABE}$ production [6], the effect of $\mathrm{pH}$ on the production profiles was investigated for Clostridium sp. A1424. The initial $\mathrm{pH}$ was around 6.0 and $\mathrm{pH}$ was maintained at a set point (6.0, 5.7, 5.5, 5.3, and 5.0) once the $\mathrm{pH}$ decreased to that point. Because glucose consumption during the $\mathrm{pH}$-controlled fermentation was expected to be higher than that of no $\mathrm{pH}$-controlled serum bottle test (Fig. 2), the initial glucose concentration was increased to $60 \mathrm{~g} / \mathrm{L}$ for avoiding carbon source limitation. The cell growth (Fig. 3a) was similar to, or slightly higher than, that with no $\mathrm{pH}$ control (Fig. 2e) except for fermentation at $\mathrm{pH} 6.0$ revealing much lower cell growth (Fig. 3a). Moreover, glucose consumption at $\mathrm{pH} 5.0$ was lower than that of other $\mathrm{pH}$-controlled cultures (Fig. 3b).

The best performance in alcohol production was obtained at $\mathrm{pH} 5.5$ after $32 \mathrm{~h}(9.43 \mathrm{~g} / \mathrm{L}$ butanol and $4.49 \mathrm{~g} / \mathrm{L}$ isopropanol) from $46.35 \mathrm{~g} / \mathrm{L}$ glucose. This result is superior to butanol and isopropanol production without $\mathrm{pH}$ control (shown in Fig. 2f) by 26.2 and $15.1 \%$, respectively. The yield $\left(Y_{\mathrm{B}}\right.$ and $\left.Y_{\mathrm{IB}}\right)$ and productivity $\left(P_{\mathrm{B}}\right.$ and $\left.P_{\mathrm{IB}}\right)$ of butanol and total alcohol at $\mathrm{pH} 5.5$ were 0.20 and $0.30 \mathrm{~g} / \mathrm{g}$, and 0.29 and $0.44 \mathrm{~g} / \mathrm{L} / \mathrm{h}$, respectively. These results are similar to those obtained with serum bottle cultivation without $\mathrm{pH}$ control.

The balance between $\mathrm{NAD}(\mathrm{P}) \mathrm{H}$ and $\mathrm{NAD}(\mathrm{P})^{+}$plays a key role in the production of solvents in clostridia. The generation of $\mathrm{NAD}(\mathrm{P}) \mathrm{H}$ in solventogenic clostridia occurs not only through the glycolytic pathway but also by the pyruvate ferredoxin oxidoreductase (PFOR) at the expense of hydrogen to produce net $\mathrm{NAD}(\mathrm{P})$
$\mathrm{H}$-consuming products such as butanol (Additional file 3: Table S1) [13]. As shown in Additional file 4: Figure S3, the total required $\mathrm{NAD}(\mathrm{P}) \mathrm{H}$ for metabolite production at $\mathrm{pH}$ 5.0-5.5 was higher than $\mathrm{NAD}(\mathrm{P}) \mathrm{H}$ from the glycolytic pathway, indicating the additional $\mathrm{NAD}(\mathrm{P}) \mathrm{H}$ generation by PFOR through the oxidation of reduced ferredoxin $\left(\mathrm{Fd}_{\text {red }}\right)$. Especially, among the results at $\mathrm{pH}$ 5.3-6.0 revealing a similar glucose consumption, the amount of $\mathrm{NAD}(\mathrm{P}) \mathrm{H}$ generated from $\mathrm{Fd}_{\text {red }}$ at $\mathrm{pH} 5.5$ accounted for up to $12.0 \%$ of the total required $\mathrm{NAD}(\mathrm{P}) \mathrm{H}$, agreeing with the best performance in alcohol production. On the other hand, the highest level of acetone was also obtained at $\mathrm{pH}$ 5.5. It seems that the generated NAD $(\mathrm{P}) \mathrm{H}$ was not sufficient for the conversion of acetone to isopropanol because of a high demand of NAD $(\mathrm{P}) \mathrm{H}$ in butanol production.

\section{Effect of the mixture of glucose and glycerol on IB fermentation: toward acetone-free and 1,3-propanediol-free butanol and IB production} Although Clostridium sp. A1424 was shown to produce mainly butanol and isopropanol, residual acetone was still detected. Overexpression of the secondary alcohol dehydrogenase gene of $C$. beijerinckii NRRL B-593 might result in a complete conversion of acetone to isopropanol, but, according to the previous reports, $C$. acetobutylicum engineered to carry the secondary alcohol dehydrogenase gene of C. beijerinckii NRRL B-593 produced less butanol than the wild-type [1].

As an alternative method for no residual acetone and no negative effect on butanol production, IB fermentation of Clostridium sp. A1424 using mixtures of glucose and glycerol was attempted as a strategy for no residual acetone and no negative effect on butanol production. We hypothesized that the high $\mathrm{NAD}(\mathrm{P}) \mathrm{H}$ levels derived from glycerol would be advantageous for the conversion of acetone to isopropanol and, more attractively for butanol production, because $\mathrm{NAD}(\mathrm{P}) \mathrm{H}$ is required to produce those alcohols. In addition, we investigated the effect of the mixture of glucose and glycerol on 1,3-PDO production.

To provide varied NAD $(\mathrm{P}) \mathrm{H}$ generation from glycolysis, various ratios of glucose to glycerol $(20: 2,18: 4,14: 8$, and 9:13) with a total concentration of $21-22 \mathrm{~g} / \mathrm{L}$ were used. Table 3 and Fig. 4 show the effect of the ratio of glucose and glycerol on IB fermentation performance. As the ratio of glycerol increased, the total $\mathrm{NAD}(\mathrm{P}) \mathrm{H}$ from glycolysis increased (Table 3) despite the decreased total carbon consumption. The cell growth and $\mathrm{pH}$ profiles were not significantly different (Fig. 4a, c, e) except for the 9:13 ratio of glucose to glycerol (Fig. 4g).

Regarding acetone production, when the ratio of glucose to glycerol was about 18:4 and 14:8, acetone was 

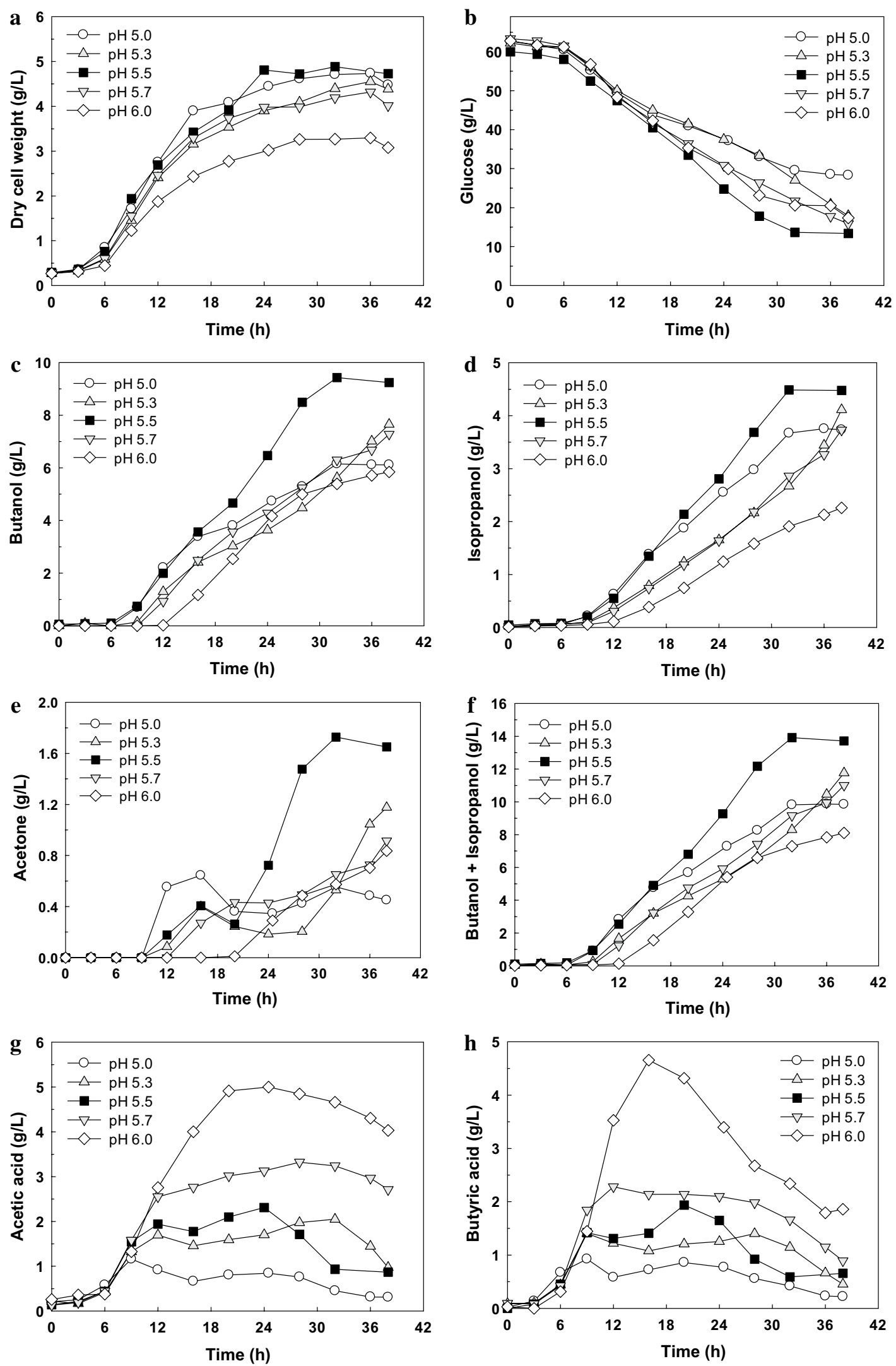
(See figure on previous page.)

Fig. 3 The $\mathrm{pH}$-controlled fermentation of Clostridium sp. A1424. a Dry cell weight, $\mathbf{b}$ glucose, $\mathbf{c}$ butanol, $\mathbf{d}$ isopropanol, e acetone, $\mathbf{f}$ butanol and isopropanol, $\mathbf{g}$ acetic acid, and $\mathbf{h}$ butyric acid. The data are from a single run

Table 3 Isopropanol-butanol (IB) fermentation with various ratios of glucose and glycerol

\begin{tabular}{|c|c|c|c|c|c|}
\hline & \multicolumn{5}{|c|}{ Ratio of glucose:glycerol (g:g) } \\
\hline & 22:0 & $20: 2$ & $18: 4$ & $14: 8^{c}$ & $9: 13^{c}$ \\
\hline \multicolumn{6}{|l|}{ Substrate consumption } \\
\hline Glucose $(\mathrm{g} / \mathrm{L})[\mathrm{mM}]$ & $\begin{array}{l}21.85_{ \pm 0.27} \\
{[121.25]}\end{array}$ & $\begin{array}{l}19.85_{ \pm 0.45} \\
{[110.16]}\end{array}$ & $\begin{array}{l}17.62_{ \pm 0.69} \\
{[97.78]}\end{array}$ & $\begin{array}{l}13.35_{ \pm 0.31} \\
{[74.10]}\end{array}$ & $\begin{array}{l}8.98_{ \pm 0.20} \\
{[49.82]}\end{array}$ \\
\hline Glycerol (g/L) [mM] & $\begin{array}{l}0 \\
{[0]}\end{array}$ & $\begin{array}{l}1.83_{ \pm 0.61} \\
{[19.82]}\end{array}$ & $\begin{array}{l}3.59_{ \pm 0.30} \\
{[38.97]}\end{array}$ & $\begin{array}{l}7.01_{ \pm 0.14} \\
{[76.08]}\end{array}$ & $\begin{array}{l}10.94_{ \pm 3.25} \\
{[118.79]}\end{array}$ \\
\hline Total carbon (mM) & 727.53 & 720.43 & 703.59 & 672.83 & 655.27 \\
\hline NAD(P)H from glycolysis (mM) & 242.51 & 259.97 & 273.50 & 300.36 & 337.21 \\
\hline $\mathrm{NAD}(\mathrm{P}) \mathrm{H}_{\mathrm{C}}(\mathrm{mol} / \mathrm{mol})^{\mathrm{d}}$ & 0.33 & 0.36 & 0.39 & 0.45 & 0.51 \\
\hline \multicolumn{6}{|l|}{ Metabolite production } \\
\hline Butanol $(\mathrm{g} / \mathrm{L})$ & $4.33_{ \pm 0.00}$ & $4.66_{ \pm 0.03}$ & $5.04_{ \pm 0.08}$ & $5.38_{ \pm 0.01}$ & $5.09_{ \pm 0.09}$ \\
\hline Isopropanol (g/L) & $2.44_{ \pm 0.05}$ & $2.24_{ \pm 0.03}$ & $2.07 \pm 0.04$ & $1.57 \pm 0.02$ & $0.83_{ \pm 0.03}$ \\
\hline Acetone $(\mathrm{g} / \mathrm{L})$ & $0.28_{ \pm 0.00}$ & $0.18_{ \pm 0.01}$ & 0 & 0 & 0 \\
\hline Butyric acid (g/L) & $0.69_{ \pm 0.02}$ & $0.73_{ \pm 0.12}$ & $0.59_{ \pm 0.00}$ & $0.98_{ \pm 0.04}$ & $1.95_{ \pm 0.03}$ \\
\hline Acetic acid (g/L) & $0.51_{ \pm 0.00}$ & $0.46_{ \pm 0.00}$ & $0.43_{ \pm 0.00}$ & $0.24_{ \pm 0.02}$ & $0.11_{ \pm 0.02}$ \\
\hline $\mathrm{NAD}(\mathrm{P}) \mathrm{H}$ requirement for product (mM) & 290.02 & 305.35 & 319.82 & 338.44 & 332.62 \\
\hline Ratio of $B / \mathrm{I}^{\mathrm{a}}(\mathrm{g} / \mathrm{g})$ & 1.78 & 2.07 & 2.43 & 3.43 & 6.14 \\
\hline$\gamma_{B}^{b}(g / g)$ & 0.20 & 0.21 & 0.24 & 0.26 & 0.26 \\
\hline$Y_{\mathrm{BB}}^{\mathrm{b}}(\mathrm{g} / \mathrm{g})$ & 0.31 & 0.32 & 0.34 & 0.34 & 0.30 \\
\hline
\end{tabular}

The values are average and one standard deviation of triplicate experiments

The fermentation was performed on serum bottle without $\mathrm{pH}$ control

The data were obtained at $28 \mathrm{~h}$ of fermentation except 9:13 (25 h)

a $\mathrm{B} / \mathrm{l}$ butanol concentration divided by isopropanol concentration

b $Y_{B}$, butanol yield ( $\mathrm{g}$ butanol/g substrate); $Y_{\mathrm{IB}}$, the sum of butanol and isopropanol yield ( $\mathrm{g}$ [butanol + isopropanol]/g substrate)

c After fermentations, 0.39 and $2.48 \mathrm{~g} / \mathrm{L}$ glycerol remained on the ratio of $14: 8$ and 9:13, respectively

${ }^{d} \mathrm{NAD}(\mathrm{P}) \mathrm{H}_{\mathrm{C}}$ : The generation of $\mathrm{NAD}(\mathrm{P}) \mathrm{H}$ mole per consumed substrate carbon mole

produced up to 0.83 and $0.10 \mathrm{~g} / \mathrm{L}$, respectively, and then completely disappeared as the fermentation was prolonged (Fig. 4d, f), clearly demonstrating the effect of glycerol addition on acetone reduction. The residual acetone was not even detected at all when the ratio of glucose to glycerol was 9:13 (Fig. 4h). Considering that Clostridium sp. A1424 utilizes glycerol and produces 1,3$\mathrm{PDO}$ as one of the main products, it is particularly noteworthy that there was no 1,3-PDO production, even with the ratio of glucose to glycerol at 9:13. When a higher glycerol ratio (e.g., glucose:glycerol at 4:17) was examined, 1,3-PDO was produced (data not shown), indicating that adjusting the glycerol content in the mixed substrates was critical in 1,3-PDO-free IB fermentation.

Even more attractively, the concentration of butanol was higher with the mixture of glucose and glycerol $(4.66-5.38 \mathrm{~g} / \mathrm{L})$ than with glucose only $(4.33 \mathrm{~g} / \mathrm{L})$. The highest butanol concentration $(5.38 \mathrm{~g} / \mathrm{L})$, yield of butanol
$(0.26 \mathrm{~g} / \mathrm{g})$, and yield of IB production $(0.34 \mathrm{~g} / \mathrm{g})$ were obtained with the ratio of glucose to glycerol at $14: 8$ (Table 3$)$. The productivity of butanol $\left(P_{\mathrm{B}}\right)$ after $16 \mathrm{~h}$ was also enhanced from $0.27 \mathrm{~g} / \mathrm{L} / \mathrm{h}$ (with glucose only) to $0.35 \mathrm{~g} / \mathrm{L} / \mathrm{h}$ (glucose to glycerol ratio at $14: 8$ ). On the other hand, isopropanol production decreased as the proportion of glycerol increased (Table 3). Accordingly, the ratio of butanol to isopropanol dramatically increased from 1.78 to 6.14 with increasing proportion of glycerol (Table 3). To the best of our knowledge, this high butanol-to-isopropanol ratio has not been obtained before with wild-type or engineered clostridia strains.

Further analysis of IB fermentation performance with regard to $\mathrm{NAD}(\mathrm{P}) \mathrm{H}$ levels was conducted on the basis of the moles of consumed carbon to compensate for the difference in the total carbon consumption and $\mathrm{NAD}(\mathrm{P})$ $\mathrm{H}$ generation capability from glucose and glycerol $(0.33$ and $0.66 \mathrm{NAD}(\mathrm{P}) \mathrm{H}$ per $\mathrm{C}$ mole of glucose and glycerol, 

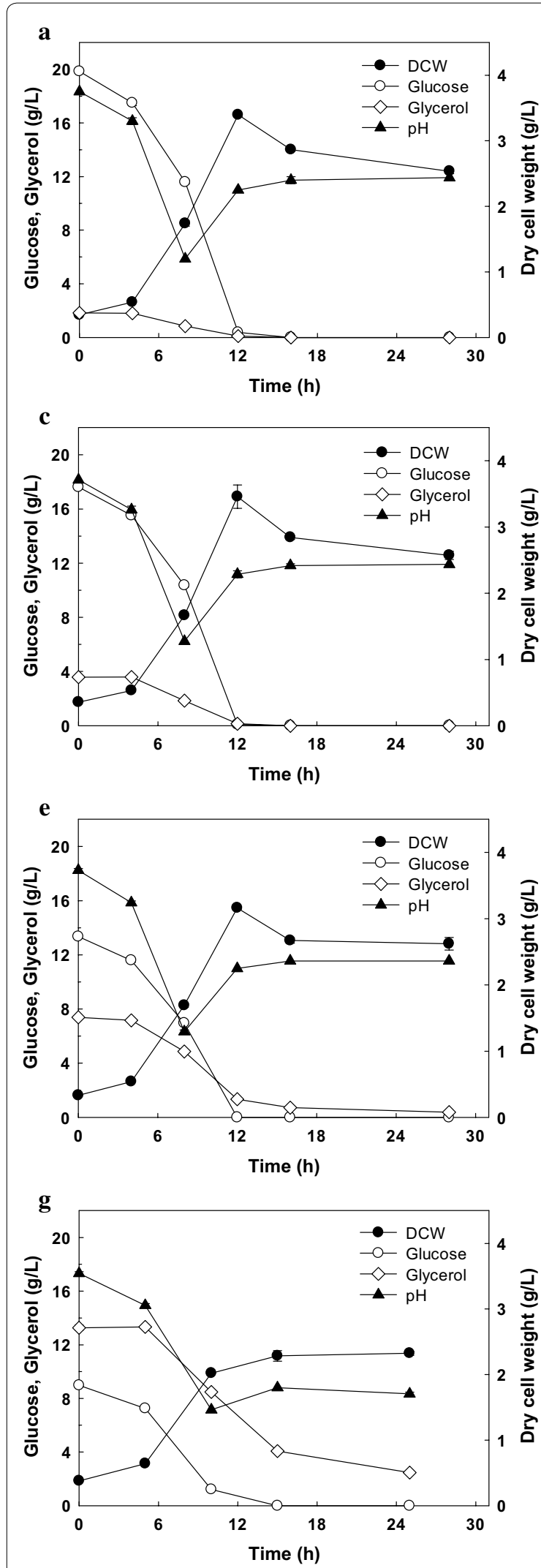

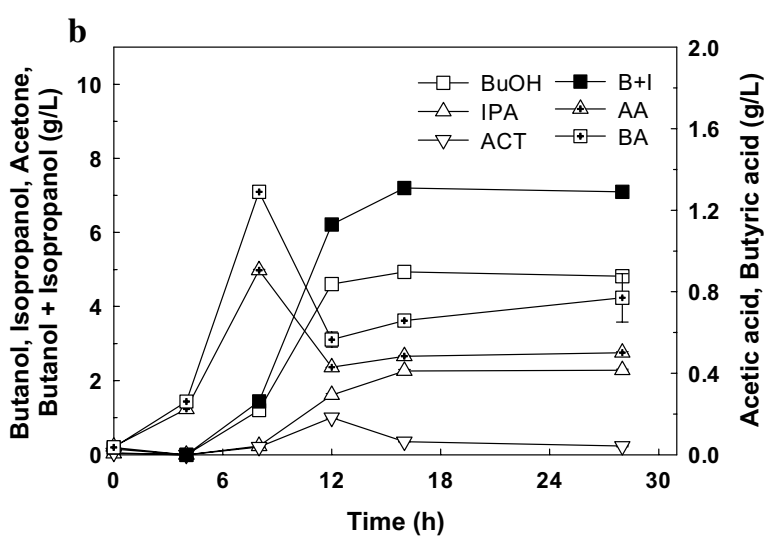

6.2
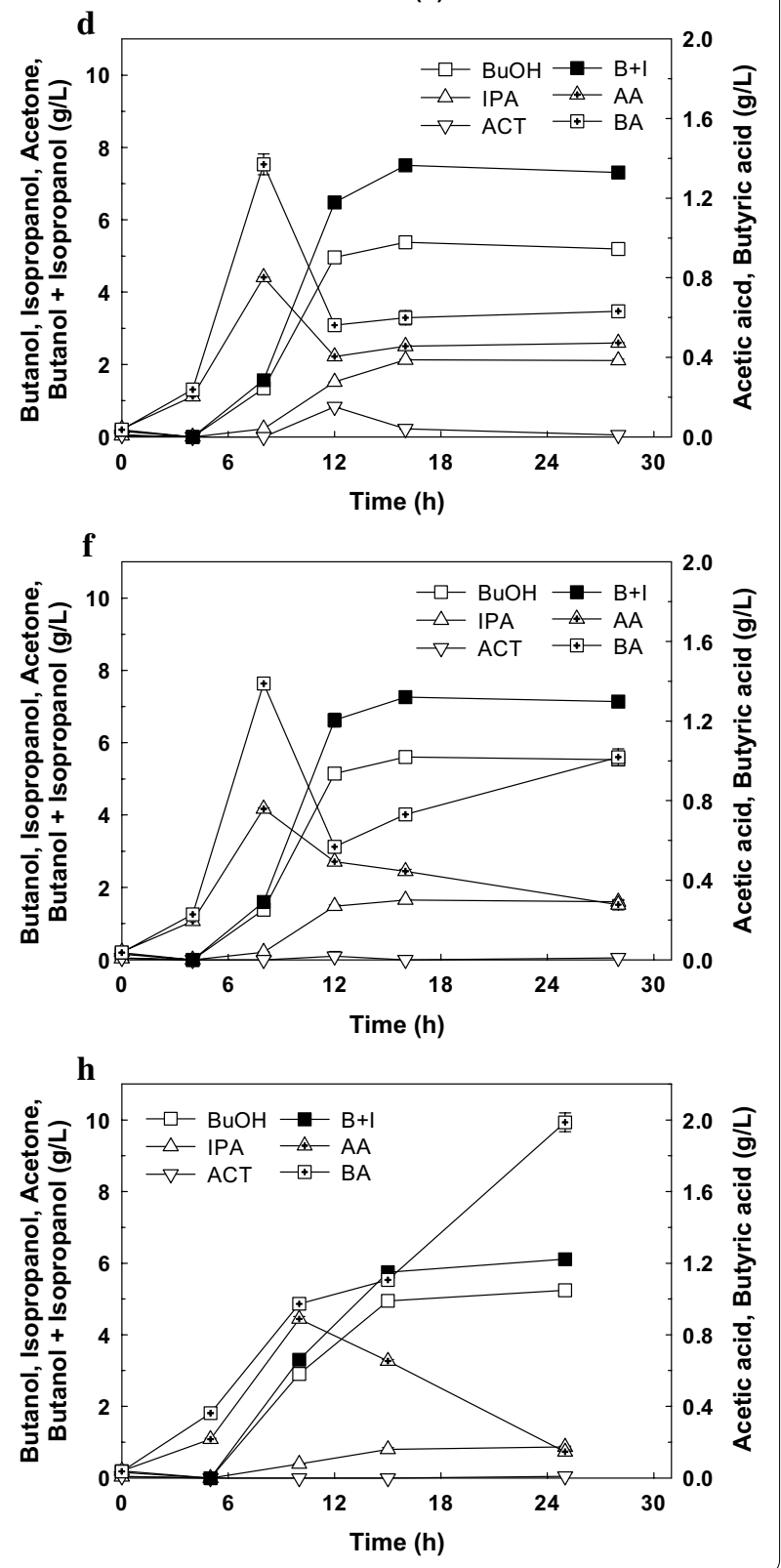
(See figure on previous page.)

Fig. 4 Effect of the mixture ratio of glucose and glycerol on isopropanol-butanol fermentation. The mass ratios of glucose and glycerol were 20:2 $(\mathbf{a}, \mathbf{b}), 18: 4(\mathbf{c}, \mathbf{d}), 14: 8(\mathbf{e}, \mathbf{f})$, and 9:13 (g, h). DCW dry cell weight, BuOH butanol, IPA isopropanol, ACT acetone, $B+$ / butanol + isopropanol, $A A$ acetic acid, $B A$ butyric acid. The fermentation was performed on serum bottles without $\mathrm{pH}$ control. Error bars represent one standard deviation of triplicate experiments

respectively). The $\mathrm{NAD}(\mathrm{P}) \mathrm{H}$ per $\mathrm{C}$ mole of consumed substrate $\left(\mathrm{NAD}(\mathrm{P}) \mathrm{H}_{\mathrm{C}}\right)$ values from the glycolysis pathway ranged from 0.36 to $0.51 \mathrm{~mol} / \mathrm{mol}$ (Table 3). As seen in Fig. $5 \mathrm{a}$, the fraction of $\mathrm{NAD}(\mathrm{P}) \mathrm{H}$ from $\mathrm{Fd}$ compared to the total $\mathrm{NAD}(\mathrm{P}) \mathrm{H}$ requirement for metabolite production decreased as the ratio of glycerol increased. Even no $\mathrm{NAD}(\mathrm{P}) \mathrm{H}$ generation from Fd seemed to be involved with the ratio of glucose to glycerol at 9:13. This indicates that increased $\mathrm{NAD}(\mathrm{P}) \mathrm{H}$ generation from glycerol likely complemented the amount of $\mathrm{NAD}(\mathrm{P}) \mathrm{H}$ required for metabolite production.

Butanol production per $\mathrm{C}$ mole of consumed substrate $\left(\mathrm{BuOH}_{\mathrm{C}}\right)$ increased with $\mathrm{NAD}(\mathrm{P}) \mathrm{H}_{\mathrm{C}}$, but, unexpectedly, it slightly decreased at $0.51 \mathrm{~mol} / \mathrm{mol}$ of $\mathrm{NAD}(\mathrm{P}) \mathrm{H}_{\mathrm{C}}$ (i.e., glucose:glycerol $=9: 13)$. Isopropanol per $C$ mole of consumed substrate $\left(\mathrm{IPA}_{\mathrm{C}}\right)$ decreased with the increase of $\mathrm{NAD}(\mathrm{P}) \mathrm{H}_{\mathrm{C}}$. Total alcohol production per $\mathrm{C}$ mole of consumed substrate $\left(\mathrm{IB}_{\mathrm{C}}\right)$ was the highest at the glucose to glycerol ratio of 14:8 (Fig. 5b). In cases of non-alcohol metabolites, acetone, and acetate production per $\mathrm{C}$ mole of consumed substrate $\left(\mathrm{ACT}_{\mathrm{C}}\right.$ and $\mathrm{AA}_{\mathrm{C}}$, respectively) decreased with the increase of $\mathrm{NAD}(\mathrm{P}) \mathrm{H}_{\mathrm{C}}$, while butyric acid production per $\mathrm{C}$ mole of consumed substrate $\left(\mathrm{BA}_{\mathrm{C}}\right)$ was the lowest at $0.39 \mathrm{~mol} / \mathrm{mol}$ of $\mathrm{NAD}(\mathrm{P}) \mathrm{H}_{\mathrm{C}}$. Overall, $\mathrm{NAD}(\mathrm{P}) \mathrm{H}_{\mathrm{C}}$ at $0.45 \mathrm{~mol} / \mathrm{mol}$ (glucose:glycerol $=14: 8$ ) revealed the best $\mathrm{BuOH}_{C}$ and $\mathrm{IB}_{C}$ without residual acetone, demonstrating efficient carbon conversion to butanol as well as total alcohols.

The main metabolic pathways in IB producing clostridia can be divided into net NAD $(\mathrm{P}) \mathrm{H}$-generating pathways such as acetate, acetone, and isopropanol producing pathways, while butyrate and butanol producing pathways are net $\mathrm{NAD}(\mathrm{P}) \mathrm{H}$-neutral or net $\mathrm{NAD}(\mathrm{P}) \mathrm{H}$-consuming ones. As seen in Fig. $5 d$, the sum of net $\mathrm{NAD}(\mathrm{P}) \mathrm{H}$-generating metabolites per $\mathrm{C}$ mole $\left([\mathrm{ACT}+\mathrm{IPA}+\mathrm{AA}]_{\mathrm{C}}\right)$ decreased with increasing $\operatorname{NAD}(\mathrm{P}) \mathrm{H}_{C}$ levels. On the other hand, the sum of butyric acid and butanol production per $C$ mole $\left([\mathrm{BuOH}+\mathrm{BA}]_{\mathrm{C}}\right)$ increased with $\mathrm{NAD}(\mathrm{P}) \mathrm{H}_{\mathrm{C}}$ levels (Fig. 5d). This result suggests that a metabolic shift likely occurred toward butyric acid and butanol production rather than acetic acid, acetone, and isopropanol production to adjust the NAD $(\mathrm{P}) \mathrm{H} / \mathrm{NAD}(\mathrm{P})^{+}$balance. In Fig. 5b, c, the carbon flow to butyric acid, not butanol, increased with $\mathrm{NAD}(\mathrm{P}) \mathrm{H}_{\mathrm{C}}$ at $0.51 \mathrm{~mol} / \mathrm{mol}$ although more $\mathrm{NAD}(\mathrm{P})$ $\mathrm{H}$ can be consumed through butanol production. This phenomenon can be explained with a very low carbon flux to acetone and isopropanol, which likely results in a relatively low level of butyric acid re-assimilation and consequently high butyric acid residual.

The strategy using glucose and a more reduced carbon source like glycerol has been studied for the control of the metabolic fluxes and $\mathrm{NAD}(\mathrm{P}) \mathrm{H}$ pools using C. acetobutylicum [36] and Clostridium butyricum [37]. The use of mixture of glucose and glycerol has also been investigated with $C$. pasteurianum to enhance butanol production $[16,17]$ and with C. beijerinckii NCIMB 8052 for in situ detoxification of furfural [27]. However, 1,3-PDO and acetone were still produced by $C$. pasteurianum and $C$. beijerinckii, respectively, grown on the mixture of glucose and glycerol. In this study, we investigated the effect of mixture of glucose and glycerol on IB production for the first time. Notably, using a mixture of glucose and glycerol allowed us to achieve acetone-free and 1,3-PDO-free butanol and IB production with Clostridium sp. A1424. More desirably, the fermentation of Clostridium sp. A1424 with glucose and glycerol together was highly efficient for the production of butanol and total alcohol (the sum of butanol and isopropanol) along with high butanol contents. This is the first report of successful increase of butanol content in IB fermentation by using a mixture of glucose and glycerol without genetic engineering.

\section{High production of butanol using mixtures of glucose and crude glycerol}

Because biodiesel-derived crude glycerol is an attractive cheap resource, we carried out IB fermentation with the mixture of glucose and crude glycerol instead of pure glycerol. Total substrate concentration was about $35.68 \mathrm{~g} / \mathrm{L}$ with the ratio of glucose to crude glycerol at 14:8. This ratio of mixed substrates yielded the highest butanol production in case of pure glycerol (Table 3).

As shown in Fig. 6, glucose (23.04 g/L) and crude glycerol $(12.64 \mathrm{~g} / \mathrm{L})$ were completely consumed within $24 \mathrm{~h}$ and $12.74 \mathrm{~g} / \mathrm{L}$ alcohol $(9.86 \mathrm{~g} / \mathrm{L}$ butanol and $2.88 \mathrm{~g} / \mathrm{L}$ isopropanol) was produced. Especially, acetone-free and 1,3-PDO-free IB fermentation was also achieved using the mixture of glucose and crude glycerol. The yields of butanol and total alcohol production per total consumed substrate were 0.28 and $0.36 \mathrm{~g} / \mathrm{g}$, respectively, and the ratio of butanol to isopropanol was 3.44. These values were almost identical to those with the ratio of glucose to pure glycerol at 14:8. Therefore, crude glycerol could 

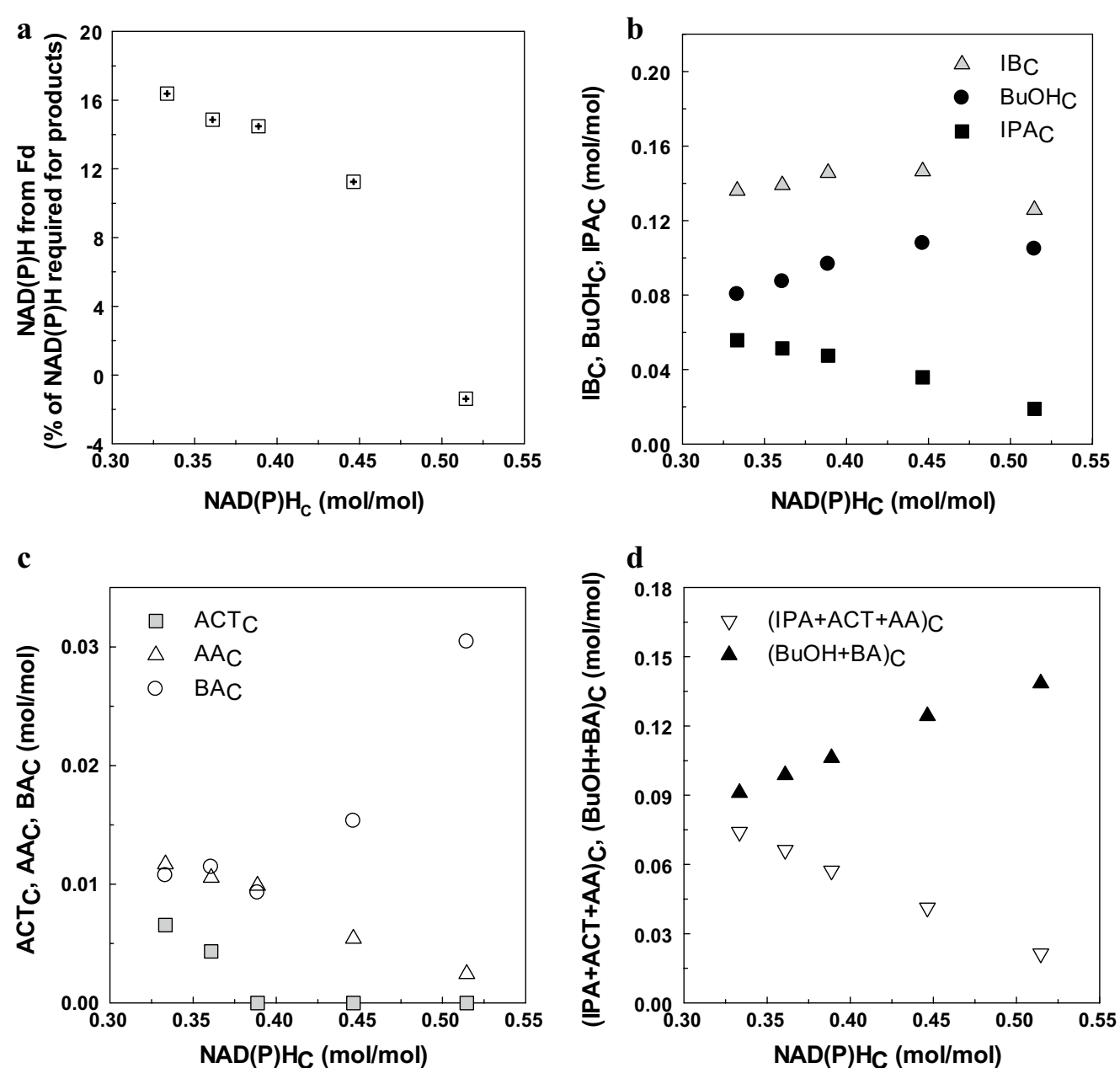

Fig. 5 Isopropanol-butanol fermentation analysis with regard to $\mathrm{NAD}(\mathrm{P}) \mathrm{H}$ levels. A subscript " $\mathrm{C}$ " means 'per $\mathrm{C}$ mole of consumed substrate.' a Fraction of $\mathrm{NAD}(\mathrm{P}) \mathrm{H}$ from Fd per required $\mathrm{NAD}(\mathrm{P}) \mathrm{H}$ for products, $\mathbf{b}$ alcohol (IB, $\mathrm{BuOH}$, and IPA) production per $\mathrm{C}$ mole of consumed substrate, $\mathbf{c}$ nonalcohol (ACT, AA, and BA) production per $\mathrm{C}$ mole of consumed substrate, d NAD(P)H-generating metabolites per $\mathrm{C}$ mole $\left([\mathrm{IPA}+\mathrm{ACT}+\mathrm{AA}]_{C}\right)$ and the other metabolites per $\mathrm{C}$ mole $\left([\mathrm{BuOH}+\mathrm{BA}]_{\mathrm{C}}\right)$. BuOH butanol, IPA isopropanol, IB isopropanol + butanol, $A C T$ acetone, $A A$ acetic acid, $B A$ butyric acid

be used as a cost-effective co-substrate on IB fermentation by Clostridium sp. A1424 without inhibitory effects of impurities in crude glycerol.

Note that the concentration of butanol from the mixed substrates $(9.86 \mathrm{~g}$ butanol/L after $24 \mathrm{~h}$ ) and that from glucose only at $\mathrm{pH} 5.5(9.43 \mathrm{~g}$ butanol/L after $32 \mathrm{~h}$ ) (Fig. 3) are similar; but, the butanol yield and productivity using the mixed substrates are 1.4-fold higher than those with glucose only at pH $5.5(0.29$ vs. $0.20 \mathrm{~g} / \mathrm{g} ; 0.41$ vs. $0.29 \mathrm{~g} / \mathrm{L} / \mathrm{h}$ ). In addition, carbon recovery of substrate to butanol and IB is also significantly effective with the mixed substrates. Figure $6 \mathrm{c}$ shows carbon recovery of substrate to butanol and isopropanol in case of; (i) IB fermentation with the mixture of glucose and crude glycerol (the ratio of 14:8) and (ii) IB fermentation with glucose only at $\mathrm{pH}$ 5.5. Carbon recovery to IB was 57.5 and $47.5 \%$ with the mixed substrates and glucose only, respectively. Notably, carbon recovery to butanol with the mixed substrates was also much higher than that with glucose (45.4 vs. $33.0 \%$ ). This is advantageous from the perspective of carbon recovery and carbon conversion to biofuel (butanol). Further study, such as the development of genetic tools and process optimization would be helpful for achieving improved yield, productivity, and concentration for IB fermentation.

\section{Conclusions}

A newly isolated Clostridium sp. A1424 was able to produce not only butanol and isopropanol from various carbon sources including glucose, but also butanol from 

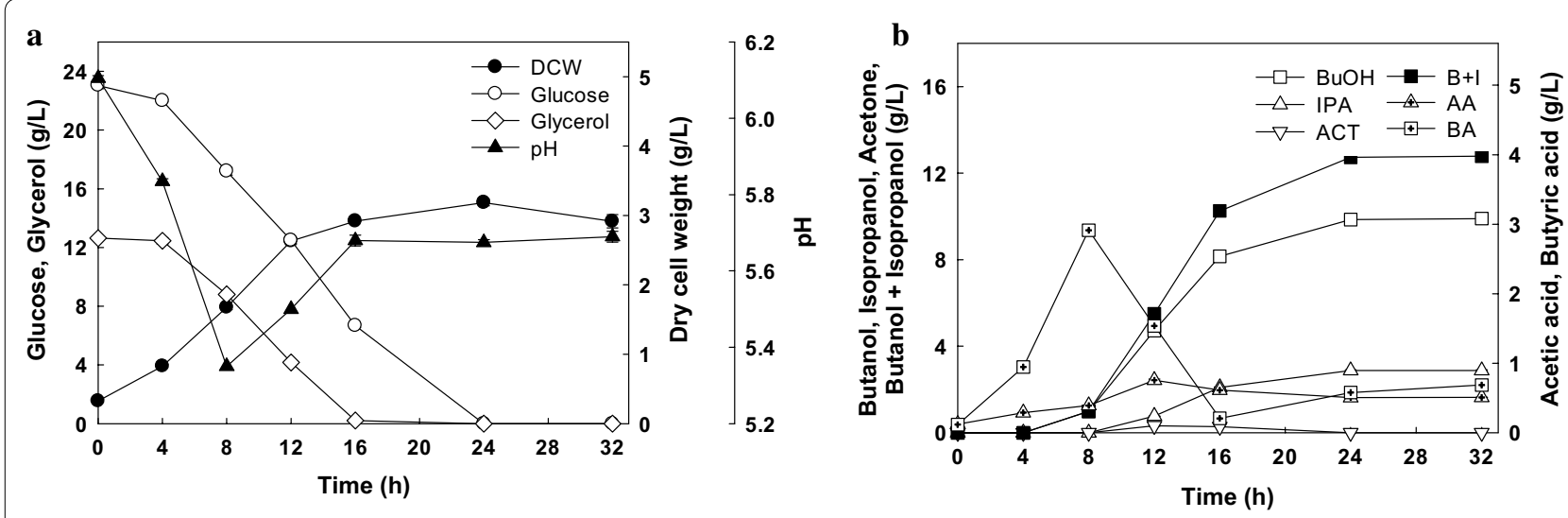

c

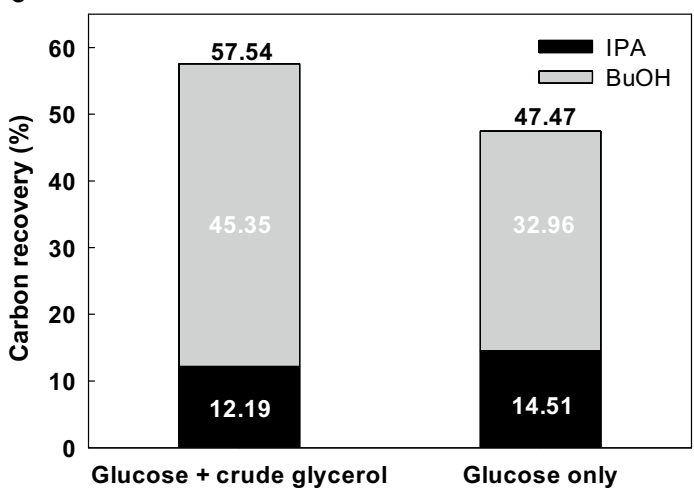

Fig. 6 Effect of the mixture of glucose and crude glycerol on isopropanol-butanol fermentation. a cell growth, glucose, glycerol, and pH, $\mathbf{b}$ metabolite production, c carbon recovery to butanol and isopropanol. DCW dry cell weight, BuOH butanol, IPA isopropanol, $A C T$ acetone, $B+I$ butanol + isopropanol, $A A$ acetic acid, $B A$ butyric acid. The fermentation was performed on serum bottles without pH control. Error bars represent one standard deviation of triplicate experiments

glycerol as the main product. The productivity and titer of butanol and total alcohol with Clostridium sp. A1424 were higher than the previous reports exploring other natural IB producers. Use of the mixture of glucose and glycerol (regardless of pure and crude glycerol) was successful to achieve acetone-free, 1,3-PDO-free, and enhanced IB production. Particularly, the performance of butanol production (yield, productivity, and selectivity) was significantly enhanced using a mixture of glucose and glycerol, compared to using glucose only. Thus, IB fermentation favoring butanol production with Clostridium sp. A1424 is especially valuable for the efficient carbon recovery to IB and butanol, a promising biofuel.

\section{Methods}

Media

Modified P2 medium (MP2) was used for seed and main cultures. The composition of medium (wt/v) was $0.6 \%$ yeast extract, $0.05 \% \mathrm{~K}_{2} \mathrm{HPO}_{4}, 0.05 \% \mathrm{KH}_{2} \mathrm{PO}_{4}, 0.2 \%$ $\left(\mathrm{NH}_{4}\right)_{2} \mathrm{SO}_{4}, 0.02 \% \mathrm{MgSO}_{4} \cdot 7 \mathrm{H}_{2} \mathrm{O}, 0.001 \% \mathrm{MnSO}_{4} \cdot \mathrm{H}_{2} \mathrm{O}$, $0.001 \% \mathrm{FeSO}_{4} \cdot 7 \mathrm{H}_{2} \mathrm{O}, 0.001 \% \mathrm{NaCl}$, and $1.95 \% \mathrm{MES}$ (2-( $N$-morpholino) ethanesulfonic acid) [12]. Various carbon sources including D-glucose, D-mannose, D-fructose, D-xylose, L-arabinose, D-galactose, D-cellobiose, sucrose, and glycerol were added to MP2 medium as a substrate at a certain concentration as occasion demanded. Crude glycerol containing $81.7 \%$ (wt/wt) of glycerol, $10.5 \%$ (wt/wt) of water, $5 \%(\mathrm{wt} / \mathrm{wt})$ of MONG (matter organic non-glycerol), 2.9\% (wt/wt) of ash, 2.4\% (wt/wt) of sodium, and less than $0.01 \%$ (wt/wt) of methanol, magnesium, and potassium was obtained from GS Caltex Corporation (South Korea) [38]. The initial pH of the medium was adjusted to 6.0 with $5 \mathrm{~N} \mathrm{KOH}$.

\section{Isolation and identification of Clostridium sp. A1424}

Diesel-oil-contaminated soil was collected from Baegun Mountain (Gyeonggi-Do, South Korea). The soil sample $(2 \mathrm{~g})$ was added to $20 \mathrm{~mL}$ of sterilized and anaerobic MP2 medium containing $2 \%(\mathrm{wt} / \mathrm{v})$ glucose; then heated at $80{ }^{\circ} \mathrm{C}$ for $30 \mathrm{~min}$. The solution was incubated at $30{ }^{\circ} \mathrm{C}$ until cell growth was observed. After confirming the cell growth with the optical density at $600 \mathrm{~nm}\left(\mathrm{OD}_{600}\right)$, the culture broth was serially diluted with $0.85 \%(\mathrm{wt} / \mathrm{v})$ sterilized saline solution. Then it was plated onto MP2 
medium agar plate containing $2 \%(\mathrm{wt} / \mathrm{v})$ glucose in an anaerobic chamber $\left(85 \% \mathrm{~N}_{2}, 10 \% \mathrm{CO}_{2}\right.$, and $5 \% \mathrm{H}_{2}$; Coy Laboratory Products, Ann Arbor, MI, USA). After the cultivation for 4 days at $30{ }^{\circ} \mathrm{C}$ in the chamber, each colony was cultivated again on MP2 liquid medium with $2 \%$ (wt/v) glucose for $48 \mathrm{~h}$ and metabolites were analyzed.

The 16S rRNA analysis and phylogenetic analysis of Clostridium sp. A1424 were accomplished as described in Lee et al. [38]. The $16 \mathrm{~S}$ rRNA sequence was deposited to GenBank with the accession number KT314078 (http://www.ncbi.nlm.nih.gov).

\section{Culture conditions}

The microorganism was stored as a spore solution in sterile distilled water at $4{ }^{\circ} \mathrm{C}$. For the activation of spores, the solution was heated at $80^{\circ} \mathrm{C}$ for $10 \mathrm{~min}$. The seed cultivation was started with inoculation of the $5 \%(\mathrm{v} / \mathrm{v})$ activated spore solution in autoclaved MP2 medium containing $2 \%$ (wt/v) glucose at $37^{\circ} \mathrm{C}$ and $200 \mathrm{rpm}$. When cell growth reached $\mathrm{OD}_{600}$ of 8.0-9.0 in the late-exponential phase, $5 \%(\mathrm{v} / \mathrm{v})$ culture solution was used to inoculate the main culture medium. Then, the main cultivation was performed at $37{ }^{\circ} \mathrm{C}$ and $200 \mathrm{rpm}$. To achieve anaerobic conditions for the seed and main cultures, the medium in the serum bottle was purged with argon gas for $20 \mathrm{~min}$ and the bottle was sealed with a butyl stopper and aluminum crimp seal [38].

For the $\mathrm{pH}$-controlled fermentations, a 3-L bench fermenter (Fermentec, South Korea) with a working volume of $1 \mathrm{~L}$ was prepared. The MP2 medium containing $6 \%$ $(\mathrm{wt} / \mathrm{v})$ glucose without MES was used. The fermenter jar was autoclaved and purged with filtered argon gas for $1 \mathrm{~h}$ to establish anaerobic conditions. Then, the $5 \%(\mathrm{v} / \mathrm{v})$ seed culture solution was inoculated. The fermentation was operated at $37^{\circ} \mathrm{C}$ and $200 \mathrm{rpm}$ and the $\mathrm{pH}$ was controlled with $5 \mathrm{~N} \mathrm{KOH}$ and $\mathrm{HCl}$ at the set point (pH 5.0-6.0). In case of bubble formation on the surface of the culture broth, 25\% (v/v) anti-foam solution (Antifoam Y-30 emulsion, Sigma Chemical Co., MO, USA) was added intermittently.

\section{Analysis and calculation}

Cell growth was monitored with OD at $600 \mathrm{~nm}$ using a spectrophotometer (Shimadzu UVmini-1240 spectrophotometer, Kyoto, Japan) and dry cell weight (DCW, g/L) was determined using a calibration curve of $\mathrm{OD}_{600}$ and $\mathrm{DCW}$. The amount of carbon sources (except sucrose), 1,3-PDO, acetic acid, and butyric acid were analyzed by HPLC (Agilent technology 1,200 series, CA, USA) composed of a refractive index detector (RID) and UV/Vis detector with a Hi-plex $\mathrm{H}$ column $(300 \times 7.7 \mathrm{~mm}$, Agilent technology, CA, USA $)$. A mobile phase was $5 \mathrm{mM}$ sulfuric acid with a flow rate of $0.6 \mathrm{~mL} / \mathrm{min}$. Sucrose content was measured using a sucrose test kit (Merck Millipore Co., Darmstadt, Germany). Acetone, isopropanol, ethanol, and butanol were analyzed using a GC (Agilent technology 6890N, CA, USA) equipped with a flame ionization detector (FID). A DB-624 column $(0.53 \mathrm{~mm} \times 30 \mathrm{~m} \times 3.0 \mu \mathrm{m}$, Agilent technology, CA, USA) was used to clearly separate each peak of ethanol and isopropanol. The production of ethanol was excluded as the detected concentration was negligible (below $0.1 \mathrm{~g} / \mathrm{L}$ ) in all experiments.

The generation of $\mathrm{NAD}(\mathrm{P}) \mathrm{H}$ from glucose and glycerol through the glycolytic pathway was calculated by multiplying ' 2 ' by the moles of consumed glucose and glycerol, respectively. The requirement of $\mathrm{NAD}(\mathrm{P}) \mathrm{H}$ for the production was calculated by multiplying $4,2,1,0$, and 0 by the number of moles of produced butanol, butyric acid, isopropanol, acetone, and acetic acid, respectively [12] (Additional file 3: Table S1).

\section{Additional files}

Additional file 1: Figure S1. The fermentation profile with xylose as a sole carbon source. (a) Cell growth, substrate consumption, and $\mathrm{pH}$, (b) products. DCW, dry cell weight; $\mathrm{BuOH}$, butanol; IPA, isopropanol; $\mathrm{ACT}$, acetone; AA, acetic acid; BA, butyric acid. Error bars represent one standard deviation of triplicate experiments.

Additional file 2: Figure S2. The fermentation profile using glucose (a and $b$ ) and xylose ( $c$ and d) as a sole carbon source with acetone in media. DCW, dry cell weight; $\mathrm{BuOH}$, butanol; IPA, isopropanol; $A C T$, acetone.

Additional file 3: Table S1. Net NADH balance per one mole of product formation from the corresponding mole of glucose and glycerol.

Additional file 4: Figure S3. Calculated NAD(P)H balance between substrates and products. The molar concentration of $\mathrm{NAD}(\mathrm{P}) \mathrm{H}$ from $\mathrm{Fd}_{\text {red }}$ was calculated as following: $M_{\mathrm{NAD}(\mathrm{P}) \mathrm{H} \text { from Fd }}=4 \times M_{\text {Butanol }}+1 \times M_{\text {Isopro- }}$ panol $+2 \times M_{\text {Butyric acid }}-2 \times M_{\text {Glucose. }}$

\section{Abbreviations}

1,3-PDO: 1,3-propanediol; IBE: mixture of isopropanol, butanol, and ethanol; ABE: mixture of acetone, butanol, and ethanol; PFOR: pyruvate ferredoxin oxidoreductase; Fd: ferredoxin; Fd $_{\text {red }}$ : reduced ferredoxin; MP2: modified P2 medium; MONG: matter organic non-glycerol; $\mathrm{OD}_{600}$ : optical density at $600 \mathrm{~nm}$.

\section{Authors' contributions}

SHY and YU conceived the study. SHY carried out the experimental works and coordinated the manuscript draft. KML and KK participated in the experimental works. SL, HMW, and YU reviewed and commented on the manuscript. YU participated in its design and coordination of the manuscript draft. All authors read and approved the final manuscript.

\section{Author details \\ ${ }^{1}$ Clean Energy Research Center, Korea Institute of Science and Technology (KIST), Hwarangno 14-gil 5, Seongbuk-gu, Seoul 02792, South Korea. ${ }^{2}$ Clean Energy and Chemical Engineering, Korea University of Science and Technol- ogy, 217 Gajeong-ro, Yuseong-gu, Daejeon 34113, South Korea. ${ }^{3}$ Department of Food Science and Biotechnology, Sungkyunkwan University (SKKU), 2066 Seobu-ro, Jangan-gu, Suwon 16419, South Korea.}

\section{Acknowledgements}

Not applicable. 


\section{Competing interests}

The authors declare that they have no competing interests.

\section{Availability of data and material}

All data generated or analyzed during this study are included in this published article and its supplementary information files.

\section{Consent for publication}

All authors approved the manuscript.

\section{Funding}

This work was supported by the National Research Council of Science and Technology (NST) grant by the Korea government (MSIP) (No. CAP-11-04KIST). The authors also appreciate further support by Korea Institute of Energy Technology Evaluation and Planning (Project No. 20143010091880) and Korea Institute of Science and Technology (KIST) Institutional Program.

Received: 12 May 2016 Accepted: 18 October 2016

Published online: 26 October 2016

\section{References}

1. Lee J, Jang Y-S, Choi SJ, Im JA, Song H, Cho JH, Papoutsakis ET, Bennett GN, Lee SY. Metabolic engineering of Clostridium acetobutylicum ATCC 824 for isopropanol-butanol-ethanol fermentation. Appl Environ Microbiol. 2012;78:1416-23.

2. Jang Y-S, Malaviya A, Cho C, Lee J, Lee SY. Butanol production from renewable biomass by clostridia. Bioresour Technol. 2012;123:653-63.

3. Bankar SB, Survase SA, Ojamo H, Granström T. Biobutanol: the outlook of an academic and industrialist. RSC Adv. 2013:3:24734-57.

4. Jones DT, Woods DR. Acetone-butanol fermentation revisited. Microbiol Rev. 1986:50:484.

5. Jang YS, Malaviya AK, Lee SY. Acetone-butanol-ethanol production with high productivity using Clostridium acetobutylicum BKM19. Biotechnol Bioeng. 2013;110:1646-53.

6. Jiang M, Chen J-N, He A-Y, Wu H, Kong X-P, Liu J-L, Yin C-Y, Chen W-F, Chen P. Enhanced acetone/butanol/ethanol production by Clostridium beijerinckii IB4 using pH control strategy. Process Biochem. 2014;49:1238-44.

7. Jiang Y, Xu C, Dong F, Yang Y, Jiang W, Yang S. Disruption of the acetoacetate decarboxylase gene in solvent-producing Clostridium acetobutylicum increases the butanol ratio. Metab Eng. 2009;11:284-91.

8. Lehmann D, Hönicke D, Ehrenreich A, Schmidt M, Weuster-Botz D, Bahl H, Lütke-Eversloh T. Modifying the product pattern of Clostridium acetobutylicum. Appl Microbiol Biotechnol. 2012;94:743-54

9. Sillers R, Al-Hinai MA, Papoutsakis ET. Aldehyde-alcohol dehydrogenase and/or thiolase overexpression coupled with CoA transferase downregulation lead to higher alcohol titers and selectivity in Clostridium acetobutylicum fermentations. Biotechnol Bioeng. 2009;102:38-49.

10. Ahn J-H, Sang B-I, Um Y. Butanol production from thin stillage using Clostridium pasteurianum. Bioresour Technol. 2011;102:4934-7.

11. Biebl H. Fermentation of glycerol by Clostridium pasteurianumbatch and continuous culture studies. J Ind Microbiol Biotechnol. 2001;27:18-26.

12. Choi O, Kim T, Woo HM, Um Y. Electricity-driven metabolic shift through direct electron uptake by electroactive heterotroph Clostridium pasteurianum. Sci Rep. 2014;4:6961.

13. Dabrock B, Bahl H, Gottschalk G. Parameters affecting solvent production by Clostridium pasteurianum. Appl Environ Microbiol. 1992;58:1233-9.

14. Moon C, Lee CH, Sang B-I, Um Y. Optimization of medium compositions favoring butanol and 1,3-propanediol production from glycerol by Clostridium pasteurianum. Bioresour Technol. 2011;102:10561-8.

15. Malaviya A, Jang Y-S, Lee SY. Continuous butanol production with reduced byproducts formation from glycerol by a hyper producing mutant of Clostridium pasteurianum. Appl Microbiol Biotechnol. 2012:93:1485-94

16. Kao W-C, Lin D-S, Cheng C-L, Chen B-Y, Lin C-Y, Chang J-S. Enhancing butanol production with Clostridium pasteurianum $\mathrm{CH}_{4}$ using sequential glucose-glycerol addition and simultaneous dual-substrate cultivation strategies. Bioresour Technol. 2013:135:324-30.
17. Sabra W, Groeger C, Sharma PN, Zeng A-P. Improved n-butanol production by a non-acetone producing Clostridium pasteurianum DSMZ 525 in mixed substrate fermentation. Appl Microbiol Biotechnol. 2014;98:4267-76.

18. Yang $Y$, Hoogewind $A$, Moon $Y H$, Day D. Production of butanol and isopropanol with an immobilized Clostridium. Bioprocess Biosyst Eng 2016;39:421-8.

19. de Gérando HM, Fayolle-Guichard F, Rudant L, Millah SK, Monot F, Ferreira NL, López-Contreras AM. Improving isopropanol tolerance and production of Clostridium beijerinckii DSM 6423 by random mutagenesis and genome shuffling. Appl Microbiol Biotechnol. 2016. doi:10.1007/ s00253-016-7302-5.

20. Survase SA, Jurgens G, Van Heiningen A, Granström T. Continuous production of isopropanol and butanol using Clostridium beijerinckii DSM 6423. Appl Microbiol Biotechnol. 2011;91:1305-13.

21. Bankar SB, Jurgens G, Survase SA, Ojamo H, Granström T. Genetic engineering of Clostridium acetobutylicum to enhance isopropanol-butanolethanol production with an integrated DNA-technology approach. Renew Energy. 2015;83:1076-83.

22. Dai Z, Dong H, Zhu Y, Zhang Y, Li Y, Ma Y. Introducing a single secondary alcohol dehydrogenase into butanol-tolerant Clostridium acetobutylicum Rh8 switches ABE fermentation to high level IBE fermentation. Biotechnol Biofuels. 2012;5:44

23. de Vrije T, Budde M, van der Wal H, Claassen PAM, López-Contreras AM. "In situ" removal of isopropanol, butanol and ethanol from fermentation broth by gas stripping. Bioresour Technol. 2013;137:153-9.

24. Collas F, Kuit W, Clément B, Marchal R, López-Contreras AM, Monot F. Simultaneous production of isopropanol, butanol, ethanol and 2,3-butanediol by Clostridium acetobutylicum ATCC 824 engineered strains. AMB Express. 2012;2:1-10.

25. Dusséaux S, Croux C, Soucaille P, Meynial-Salles I. Metabolic engineering of Clostridium acetobutylicum ATCC 824 for the high-yield production of a biofuel composed of an isopropanol/butanol/ethanol mixture. Metab Eng. 2013;18:1-8

26. Lee S-M, Cho MO, Park CH, Chung Y-C, Kim JH, Sang B-I, Um Y. Continuous butanol production using suspended and immobilized Clostridium beijerinckii NCIMB 8052 with supplementary butyrate. Energy Fuels. 2008:22:3459-64

27. Ujor V, Agu CV, Gopalan V, Ezeji TC. Glycerol supplementation of the growth medium enhances in situ detoxification of furfural by Clostridium beijerinckii during butanol fermentation. Appl Microbiol Biotechnol. 2014;98:6511-21.

28. Biebl H, Spröer C. Taxonomy of the glycerol fermenting Clostridia and description of Clostridium diolis sp. nov. Syst Appl Microbiol. 2002;25:491-7

29. Kaur G, Srivastava AK, Chand S. Bioconversion of glycerol to 1,3-propanediol: a mathematical model-based nutrient feeding approach for high production using Clostridium diolis. Bioresour Technol. 2013;142:82-7.

30. Gungormusler M, Gonen C, Azbar N. Continuous production of 1,3-propanediol using raw glycerol with immobilized Clostridium beijerinckii NRRL B-593 in comparison to suspended culture. Bioprocess Biosyst Eng. 2011;34:727-33.

31. Ezeji T, Blaschek HP. Fermentation of dried distillers' grains and solubles (DDGS) hydrolysates to solvents and value-added products by solventogenic clostridia. Bioresour Technol. 2008;99:5232-42.

32. Chen C-K, Blaschek HP. Acetate enhances solvent production and prevents degeneration in Clostridium beijerinckii BA101. Appl Microbiol Biotechnol. 1999;52:170-3.

33. Zhu L, Dong H, Zhang Y, Li Y. Engineering the robustness of Clostridium acetobutylicum by introducing glutathione biosynthetic capability. Metab Eng. 2011;13:426-34.

34. Formanek J, Mackie R, Blaschek HP. Enhanced butanol production by Clostridium beijerinckii BA101 grown in semidefined P2 medium containing 6 percent maltodextrin or glucose. Appl Environ Microbiol. 1997;63:2306-10.

35. Ezeji TC, Qureshi N, Blaschek HP. Bioproduction of butanol from biomass: from genes to bioreactors. Curr Opin Biotechnol. 2007;18:220-7.

36. Vasconcelos I, Girbal L, Soucaille P. Regulation of carbon and electron flow in Clostridium acetobutylicum grown in chemostat culture at neutral pH on mixtures of glucose and glycerol. J Bacteriol. 1994;176:1443-50. 
37. Saint-Amans S, Girbal L, Andrade J, Ahrens K, Soucaille P. Regulation of carbon and electron flow in Clostridium butyricum VPI 3266 grown on glucose-glycerol mixtures. J Bacteriol. 2001;183:1748-54.
38. Cho S, Kim T, Woo HM, Kim Y, Lee J, Um Y. High production of 2,3-butanediol from biodiesel-derived crude glycerol by metabolically engineered Klebsiella oxytoca M1. Biotechnol Biofuels. 2015;8:1-12.
Submit your next manuscript to BioMed Central and we will help you at every step:

- We accept pre-submission inquiries

- Our selector tool helps you to find the most relevant journal

- We provide round the clock customer support

- Convenient online submission

- Thorough peer review

- Inclusion in PubMed and all major indexing services

- Maximum visibility for your research

Submit your manuscript at www.biomedcentral com/submit
() Biomed Central 